\title{
THE IMPACT OF SELECTED GROUPS OF NON-COMMUNICABLE DISEASE DEATHS ON LIFE EXPECTANCY IN THE SLOVAK REPUBLIC
}

\author{
Beáta Gavurová1, Tatiana Vagašová1, Sylvia Dražilová2, Peter Jarčuška ${ }^{3}$ \\ ${ }^{1}$ Faculty of Economics, Technical University of Košice, Košice, Slovak Republic \\ ${ }^{2}$ Department of Internal Medicine, Hospital Poprad, Poprad, Slovak Republic \\ ${ }^{3} 1$ st Department of Internal Medicine, University Hospital and Faculty of Medicine, Pavol Jozef Šafárik University in Košice, Košice, Slovak \\ Republic
}

\section{SUMMARY}

Aim: The aim of this study was to compute the potential gains in life expectancy (PGLEs) if the five main groups of non-communicable disease deaths were eliminated in the Slovak population during 1996-2014, and to decompose PGLEs by five-year age groups.

Methods: PGLEs were computed from mortality reports for deaths from ischaemic heart disease (120-25), cerebrovascular diseases (160-169), cancer (C00-C97), diabetes mellitus (E10-E14), and chronic respiratory diseases (J30-J98) using the life table decomposition technique.

Results: In 2014, life expectancy at birth was 76.87 years compared to 72.87 in 1996. The highest impact on life expectancy was recorded for ischaemic heart disease and PGLEs have changed from 3.9 years to 4.6 over 1996-2014. However, the trends for other diseases did not fluctuate. The PGLEs of cancer, as the second most influential disease, increased from 3.3 years to 3.6. Conversely, a slight decline was observed in cerebrovascular diseases from 1.13 years to 1.12 , and diabetes mellitus from 0.14 years to 0.13 . The proportion of diabetes mellitus and chronic respiratory diseases in PGLEs was low, approaching zero. As far as PGLEs among age groups in 2014 are concerened: whereas PGLEs for ischaemic heart disease mortality reduction are very similar among all age groups they are mostly on the decrease from other causes of death. However, PGLEs reached a value of 0.13 years in the $0-54$ years age-group for diabetes mellitus; this means that the number of years of life lost are the same for 54 year old people and younger, with the impact of diabetes mellitus declining at age 55 and over. The same scenario is apparent for cerebrovascular diseases. The impact of mortality from other causes of death is decreasing with age.

Conclusions: Our findings suggest that optimum benefit would be gained from prevention programs for reduction of ischaemic heart disease mortality in all age groups.

Key words: life expectancy, potential gains in life expectancy, non-communicable disease, standardised mortality rate, Slovak Republic

Address for correspondence: P. Jarčuška, 1st Department of Internal Medicine, University Hospital and Faculty of Medicine, Pavol Jozef Šafárik University in Košice, Trieda SNP 1, 04011 Košice, Slovak Republic. E-mail: peter.jarcuska@upjs.sk

https://doi.org/10.21101/cejph.a4954

\section{INTRODUCTION}

Globally, the ageing of population and extension of life expectancy at birth are inevitably coupled with the higher prevalence of chronic diseases $(1,2)$. By WHO one of the aims of healthy ageing is to ensure up to 2020 an increase of $20 \%$ in life expectancy at age 65 years and give population over 65 years an opportunity to play an active social role (3). The most optimistic projection scenarios for the future development of mortality in Slovakia predict by 2060 the increase in life expectancy at birth over 84.7 years (an increase of almost 12.4 years) for men and more than 89.1 years (an increase of more than 9.6 years) for women (4). The current rates of increase in mortality from circulatory diseases and cancer suggest unfavourable prospects (5). Circulatory diseases, mainly ischaemic heart disease and cerebrovascular diseases, are the most numerous and significant throughout the non-communicable diseases (6).
Overall mortality, as well as their groups (according to ICD 10), have just been the significant components of life expectancy which is considered the aggregate indicator of the population's health status (7). In general, life expectancy is the average number of years that $x$-years old persons could be expected to live if current age-specific mortality rates remain constant throughout their lifetimes (7). An aggregate character of life expectancy lies in its usefulness for reflecting the effectiveness of systematic, long-term interventions in primary and secondary prevention in the population's health. Life expectancy is affected by many factors, e.g. economy, quality of health care, life style, life and work condition, environment, and others. According to the latest available data in 2014, average life expectancy at birth of the population demonstrated 76.9 years for Slovakia, compared to 80.6 years in OECD countries and 80.6 years in the EU-28 $(8,9)$.

An alternative way how to measure the impact of decreasing cause-specific mortality rates on the improvement of life expect- 
ancy is to remove a cause of death and to calculate based on life tables the potential gains in life expectancy (PGLEs). PGLEs take account the size and age structure of population allowing the comparison across countries.

The aim of the paper is to examine the impact of the major causes of death on the life expectancy of the Slovak population and the changing trends in health status between 1996 and 2014. Previous studies (10-14) have explored life tables containing potential gains in life expectancy (PGLEs) as a research method to determine the impact of diseases with the highest prevalence causing death on the life expectancy of population. However, most of these studies have focused on the overall groups of causes of death with relation to the demography but no with the specific implications on health interventions. For instance, Lai and Hardy (11) compared the PGLEs with the years of potential life lost (YPLL) by race and gender group from HIV, heart diseases, and cancer for US population. They found that better indicator for the measuring impact of disease deaths on a population is PGLEs compared to YPLL because it is not influenced by the age and size population structure. In China, Liu et al. (12) proved that deaths from accidental injuries together with chronic diseases play a major role in influencing life expectancy. Conti et al. (13) found that AIDS and accidents have higher impact on life expectancy when consider working group (15-64 years), rather than 50\% reduction in cardiovascular diseases deaths. Generally, it is necessary to observe a neglected potential of the main causes of death and to encourage steps in the increase of life expectancy.

\section{MATERIALS AND METHODS}

Under the conditions of the contract, data on the number of deaths by five-year age groups for the period 1996-2014 were obtained from National Health Information Centre of Slovakia. Data on the mid-year population at the age groups in every year were downloaded from the Statistical Office of the Slovak Republic.

PGLE reflects how many years on average a person would live, if a given cause of death was eliminated. In other words, PGLE expresses years of life lost resulting from a certain diseases in an age group. So, life expectancy could be extended for these years. The higher PGLE, the higher impact of the disease on life expectancy is.

For calculation of PGLEs it was needed to construct the life tables and the specific life tables regarding causes of deaths in the Slovak Republic in every year by the methodical tutorials of Demographic Research Centre (15) and National Vital Statistics Reports (16). We examined the life expectancy (ex) expressing the all causes of deaths and cause-eliminated life expectancy $\left(e_{x}^{(-i)}\right)$ by elimination of the certain causes of deaths. The Tenth Revision of the International Classification of Disease (ICD-10) was used to specify causes of death included in this analysis: ischaemic heart disease (I20-I25), cerebrovascular diseases (I60-I69), cancer (C00-C97), diabetes mellitus (E10-E14), and chronic respiratory diseases (J30-J98). We selected these diseases because they are the main types of non-communicable diseases, also known as chronic diseases, that significantly burden the Slovak health system and belong to the most often causes of death in Slovakia.
Cause-eliminated life expectancy ( $e_{x}^{(-i)}$ ) was the result from analysis cause-specific mortality and was calculated from the abridged life table minus causes of death.

According to the Demographic Research Centre, the first step is the calculation of the probabilities of survival $\left({ }_{n} p_{x}\right)$ from the all-caused abridged life tables with the formula:

$$
{ }_{n} p_{x}=1-{ }_{n} q_{x}
$$

where $x$ - the exact age; $n$ - the number of years in the age interval; ${ }_{n} q_{x}$ - the probability of dying between the beginning of an age interval and before reaching the end of that age interval.

Then, the probabilities of death eliminating the ith cause $\left({ }_{n} q_{x}^{(-i)}\right)$ were estimated by:

$$
{ }_{n} q_{x}^{(-i)}=1-{ }_{n} p_{x}^{\left(\frac{{ }_{n} D_{x}-{ }_{n} D_{x}^{i}}{{ }^{D} D_{x}}\right)}
$$

where ${ }_{n} D_{x}$ - the number of deaths in the age interval $x$ to $x+$ $n$ for all causes; ${ }_{n} D_{x}^{i}$ - the number of deaths in the age interval $x$ to $x+n$ attributable to the $\mathrm{i}_{\text {th }}$ cause of death.

Arias et al. (16) report the number of person-years lived $\left({ }_{n} L_{x}^{(-i)}\right)$ in the age interval $x$ to $x+n$ was estimated for ages 0 , $1,5,10, \ldots \ldots, 95$ by the formula:

$$
{ }_{n} L_{x}^{(-i)}=\left(n-{ }_{n} f_{x}\right) \cdot l_{x}^{(-i)}+{ }_{n} l_{x} \cdot l_{x+n}^{(-i)}
$$

where $n=1$ for $x=0, n=4$ for $x=1$, and $n=5$ for $x=5,10, \ldots$, 95; ${ }_{n} l_{x}$ - the number of persons from the original life table who survive to the beginning of each age interval; $l_{x}^{(-i)}$ - the number of survivals from life table due to the ith causes; $L_{x}$ - the number of person-years from the original life table within an age interval $x$ to $x+n$, and the quantities ${ }_{n} f_{x}$ were estimated from the all-cause life table by:

$$
{ }_{n} f_{x}=\frac{n \cdot{ }_{n} l_{x}-{ }_{n} L_{x}}{l_{x}-l_{x+n}}
$$

The last step is to calculate the number of person-years lived after exact age $x\left(T_{x}^{(-i)}\right)$ by:

$$
T_{x}^{(-i)}=L_{x}^{(-i)}+L_{x+1}^{(-i)}+\cdots+L_{95+}^{(-i)}
$$

Finally, the cause-eliminated life expectancy $\left(e_{x}^{(-i)}\right)$ is calculated as:

$$
e_{x}^{(-i)}=\frac{T_{x}^{(-i)}}{l_{x}^{(-i)}}
$$

Subsequently, the PGLE of a disease in a certain year is calculated as the difference between cause-eliminated life expectancy $\left(e_{x}^{(-i)}\right)$ and life expectancy (ex) in the same year.

$$
P G L E=e_{x}^{(-i)}-e_{x}
$$

Mortality rates were age-standardised to the revised European standard population (17) using the method of direct standardisation to eliminate variances resulted from differences in age structures of the population over time. 


\section{RESULTS}

\section{Trends of Life Expectancy and Disease Mortality}

Between 1996 and 2014, the life expectancy and disease mortality in the Slovak Republic changed significantly. Life expectancy at birth in Slovakia increased by 4 years - from 72.9 years in 1996 to 76.9 in 2014 . The standardised mortality rates of cerebrovascular diseases fell from 184.5/100,000 to 140.7/100,000; diabetes mellitus decreased from 19.2/100,000 to $15.3 / 100,000$; ischaemic heart disease from $528.6 / 100,000$ to 446.2/100,000; and cancer from 334.2/100,000 to 316.4/100,000. However, the standardised mortality rates of chronic respiratory diseases showed a very small increase from 24.9/100,000 to 26.6/100,000 (Fig. 1).

\section{Trends of Potential Gains in Life Expectancy from 1996-2014}

The importance of the various causes of death is measured by the gain in life expectancy when a specified cause of death is eliminated.
During the time span 1996-2014, the highest PGLEs were recorded for ischaemic heart disease, followed by cancer, cerebrovascular diseases, chronic respiratory diseases, and diabetes mellitus (Fig. 2).

Compared to the cyclical changes in the trends of ischaemic heart disease, the variability of other diseases was low. The rising rate of chronic respiratory diseases was the highest (an increase of $45 \%$ ), from 0.17 to 0.25 years during 1996-2014, although their impacts on life expectancy are not so marked. On the contrary, the highest impacts on life expectancy result of elimination of ischaemic heart disease and cancer, respectively, from 3.92 in 1996 to 4.56 in 2014 (an increase of 16\%) and from 3.28 to 3.57 (an increase of 9\%). The PGLEs of diabetes mellitus decreased from 0.14 to 0.13 (a drop of 7\%), similarly, for cerebrovascular diseases from 1.13 to 1.12 (a drop of $0.7 \%$ ). In particular, the impact on life expectancy, resulting of elimination of diabetes mellitus and chronic respiratory diseases, are not so remarkable.

\section{Potential Gains in Life Expectancy in 2014}

In 2014, life expectancy at birth for the Slovak population was 76.9 years, calculated from the general life table. Table 1 shows the

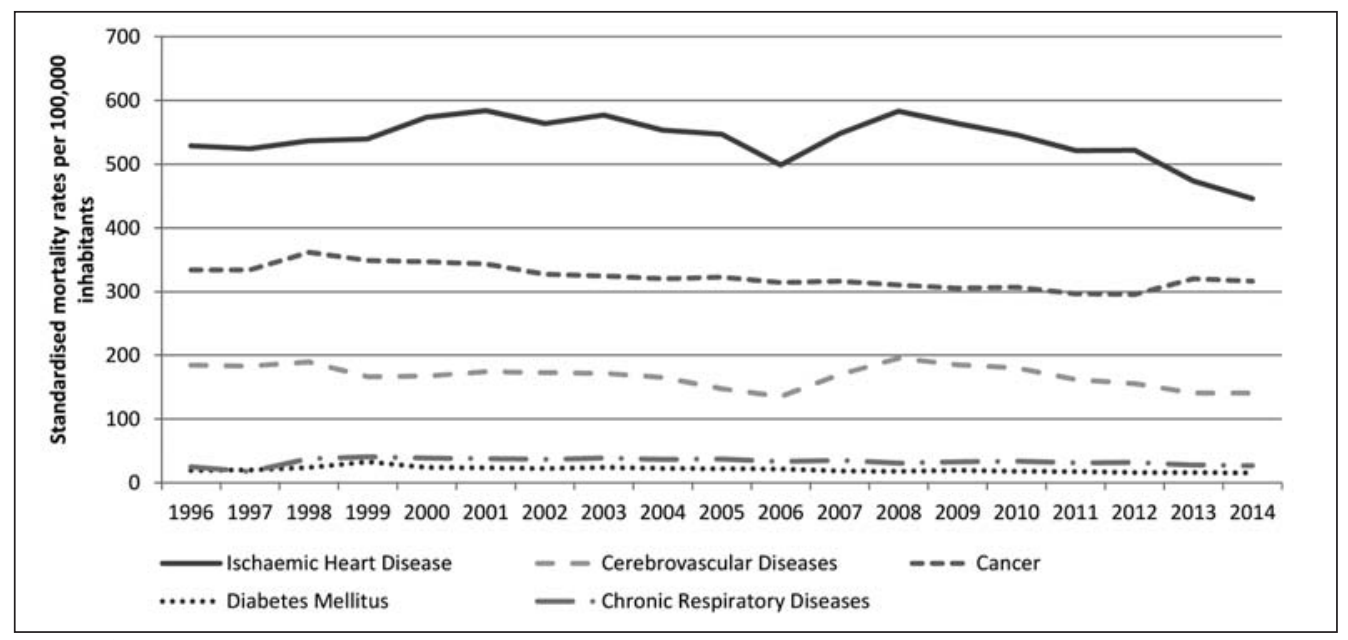

Fig.1. Standardised mortality rates per 100,000 inhabitants for the groups of chronic diseases in the Slovak Republic, $1996-2014$.

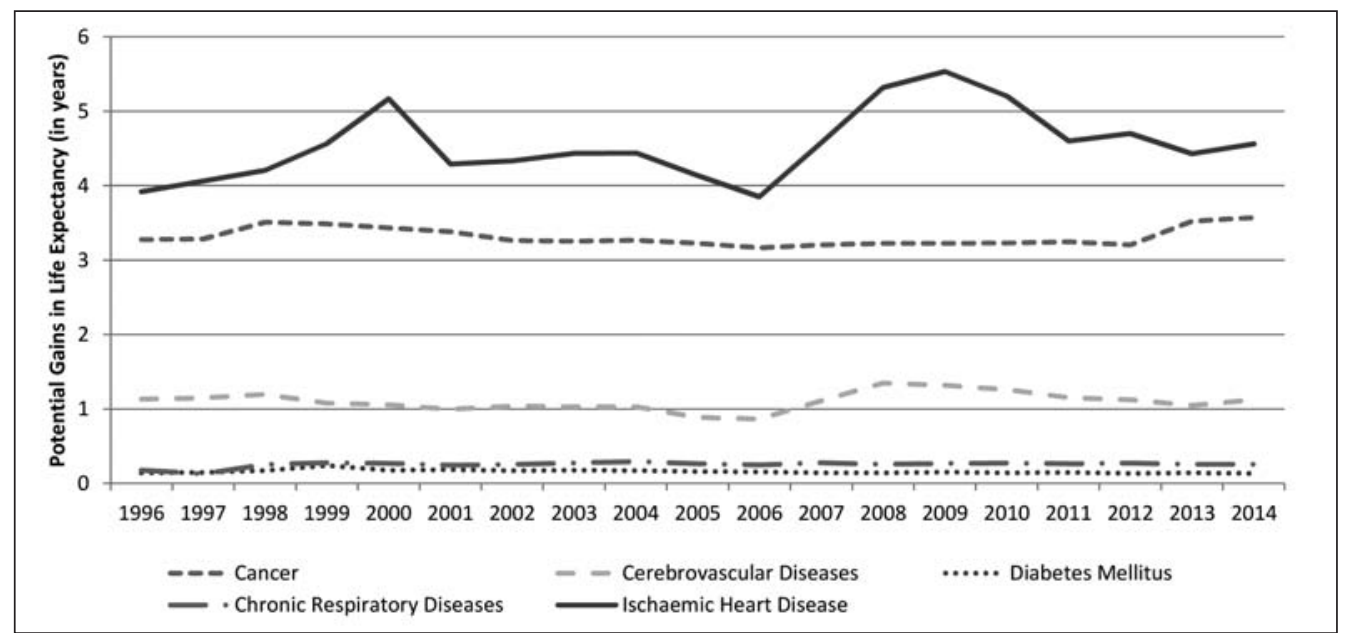

Fig. 2. Potential gains in life expectancy (in years) for the Slovak population by reductions of deaths for groups of chronic diseases, 1996-2014. 
Table 1. Potential gains in life expectancy (in years) at age groups by elimination of the groups of chronic diseases, based on 2014 mortality data

\begin{tabular}{|c|c|c|c|c|c|c|c|c|c|c|c|}
\hline \multirow{3}{*}{$\begin{array}{l}\text { Age } \\
\text { group }\end{array}$} & \multirow{3}{*}{$\begin{array}{l}\text { LE without } \\
\text { elimination }\left(e_{x}\right)\end{array}$} & \multicolumn{10}{|c|}{ Elimination of } \\
\hline & & \multicolumn{2}{|c|}{ IHD } & \multicolumn{2}{|c|}{ CBVD } & \multicolumn{2}{|c|}{$\mathrm{CA}$} & \multicolumn{2}{|c|}{ DM } & \multicolumn{2}{|c|}{ CRD } \\
\hline & & $e_{x}^{(-i)}$ & gain & $e_{x}^{(-i)}$ & gain & $e_{x}^{(-i)}$ & gain & $e_{x}^{(-i)}$ & gain & $e_{x}^{(-i)}$ & gain \\
\hline 0 & 76.87 & 81.43 & 4.56 & 77.99 & 1.12 & 80.44 & 3.57 & 77.00 & 0.13 & 77.12 & 0.25 \\
\hline 01-04 & 76.31 & 80.90 & 4.59 & 77.44 & 1.13 & 79.90 & 3.59 & 76.44 & 0.13 & 76.56 & 0.25 \\
\hline 05-09 & 72.39 & 76.98 & 4.59 & 73.51 & 1.13 & 75.97 & 3.58 & 72.52 & 0.13 & 72.63 & 0.25 \\
\hline 10-14 & 67.43 & 72.02 & 4.60 & 68.56 & 1.13 & 71.01 & 3.58 & 67.56 & 0.13 & 67.67 & 0.25 \\
\hline 15-19 & 62.47 & 67.07 & 4.60 & 63.60 & 1.13 & 66.04 & 3.57 & 62.60 & 0.13 & 62.71 & 0.24 \\
\hline $20-24$ & 57.58 & 62.19 & 4.61 & 58.71 & 1.13 & 61.14 & 3.56 & 57.72 & 0.13 & 57.82 & 0.24 \\
\hline $25-29$ & 52.72 & 57.33 & 4.62 & 53.85 & 1.13 & 56.26 & 3.55 & 52.85 & 0.13 & 52.95 & 0.24 \\
\hline $30-34$ & 47.85 & 52.48 & 4.63 & 48.98 & 1.13 & 51.39 & 3.54 & 47.99 & 0.13 & 48.09 & 0.24 \\
\hline $35-39$ & 43.03 & 47.67 & 4.64 & 44.16 & 1.13 & 46.55 & 3.52 & 43.16 & 0.13 & 43.26 & 0.23 \\
\hline 40-44 & 38.28 & 42.93 & 4.65 & 39.41 & 1.13 & 41.76 & 3.48 & 38.41 & 0.13 & 38.51 & 0.23 \\
\hline 45-49 & 33.61 & 38.28 & 4.66 & 34.73 & 1.12 & 37.06 & 3.44 & 33.74 & 0.13 & 33.84 & 0.23 \\
\hline 50-54 & 29.14 & 33.81 & 4.67 & 30.24 & 1.10 & 32.48 & 3.34 & 29.27 & 0.13 & 29.36 & 0.22 \\
\hline 55-59 & 24.88 & 29.55 & 4.68 & 25.97 & 1.10 & 28.02 & 3.14 & 25.00 & 0.12 & 25.09 & 0.22 \\
\hline 60-64 & 20.92 & 25.59 & 4.67 & 21.99 & 1.07 & 23.75 & 2.82 & 21.04 & 0.12 & 21.13 & 0.21 \\
\hline $65-69$ & 17.23 & 21.92 & 4.68 & 18.28 & 1.05 & 19.63 & 2.40 & 17.34 & 0.11 & 17.42 & 0.19 \\
\hline 70-74 & 13.73 & 18.43 & 4.70 & 14.73 & 1.00 & 15.65 & 1.92 & 13.83 & 0.10 & 13.90 & 0.17 \\
\hline 75-79 & 10.51 & 15.22 & 4.71 & 11.44 & 0.93 & 11.96 & 1.45 & 10.59 & 0.08 & 10.65 & 0.14 \\
\hline 80-84 & 7.74 & 12.44 & 4.70 & 8.57 & 0.83 & 8.75 & 1.01 & 7.80 & 0.06 & 7.84 & 0.11 \\
\hline 85-89 & 5.62 & 10.31 & 4.69 & 6.30 & 0.69 & 6.27 & 0.65 & 5.66 & 0.04 & 5.69 & 0.07 \\
\hline $90-94$ & 4.15 & 8.80 & 4.65 & 4.67 & 0.52 & 4.54 & 0.40 & 4.18 & 0.04 & 4.20 & 0.05 \\
\hline $95+$ & 3.75 & 8.38 & 4.63 & 4.05 & 0.30 & 3.91 & 0.15 & 3.78 & 0.03 & 3.78 & 0.03 \\
\hline
\end{tabular}

LE - life expectancy; ex - life expectancy without elimination; $e_{x}^{(-t)}$ - cause-eliminated life expectancy; IHD - ischaemic heart disease; CBVD - cerebrovascular diseases; $\mathrm{CA}$ - cancer; DM - diabetes mellitus; CRD - chronic respiratory diseases

PGLEs at birth and for five-year age groups through the elimination in mortality from ischaemic heart disease, cerebrovascular diseases, cancer, diabetes mellitus, and chronic respiratory diseases. The values of PGLEs at birth resulting from these causes of death were respectively, 4.56, 1.12, 3.57, 0.13, 0.25 years. It is noteworthy that PGLEs of ischaemic heart disease mortality reduction are very similar among age groups, while from other causes of death are partially decreasing. This means that the impact of IHD mortality elimination is comparable among all age categories what reflects to the very high proportion of IHD mortality in elderly. For example, after elimination of IHD deaths, a person at birth could be expected to live 4.56 years longer than the actual LE at birth (76.9 years). Similarly, a person at 75-79 years old could live 4.71 years longer than actual LE at this age group (10.5 years). On the other hand, the impact of mortality from other causes of death is mostly decreasing with age.

Commonly, as one would appreciate, the elimination of a disease results in rather lower rise in life expectancy at older ages. It is seemed in cancer, as the PGLEs continuously decrease until age $95+$, reaching a value that is very low compared with the PGLE at birth, from 3.57 to 0.15 years.

Cerebrovascular diseases have reached the third largest impacts on LE. The PGLEs are nearly the same up to the $40-44$ years old, similarly for diabetes mellitus up to the 50-54 aged. According to the hypothesis of the elimination of diabetes mellitus, the PGLE at the value 0.13 means the years of life lost which are the same for 54 years old people and younger. This shows that people in working age groups could gain most benefits from the diseases elimination.

Chronic respiratory diseases represent the smallest impact on life expectancy. Their excluding had the slowly falling effect on life expectancy among age groups. For instance, life expectancy extended by an additional 0.25 years at ages $0-14,0.24$ years at ages 15-34, etc., approaching zero.

\section{DISCUSSION}

Our results demonstrate competing risks of death as candidate diseases for prevention. Gains in life expectancy from complete elimination of the disease evaluate the burden of disease in public health. These findings have implications for making decisions in health policy, mainly on allocating of scarce resources. Total elimination of a certain cause of death is not likely, on the other hand, it provides the real strength to the other competing risks of causes of death. 
In terms of gained years, the highest benefit would be obtained by prevention programs for reduction of IHD mortality among all age groups. From the second half of the twentieth century, changing economic, social and demographic profiles led to the emergence of chronic diseases. Slovakia has belonged to the leading countries with the highest prevalence of cardiovascular disease mortality. Their growth depends largely on population's lifestyle that belongs to the modifiable risk factors. The interventions, like cheaper healthy foods, on the contrary, taxation of unhealthy foods, and their correct marking according to the amount of sugar, fats, salt and energy value, should be implemented. Thus, it is necessary to carry out prospective and intervention studies resulting in the early identification and decrease of risk factors, subsequently, in the reduction of mortality.

It is disturbing that the impact of cancer on life expectancy has been nearly unchangeable since 1996. Moreover, PGLEs of cancer have slightly increased for the last three years, in spite of the modern medicaments and treatment techniques. In addition to the risk factors, health care professionals play a major role in spreading awareness of cancer prevention. Responsibilities of general practitioners are mostly focused on the screening and early diagnosis. General practitioner should play a key role in the phase that precedes the diagnosis, for instance, routinely providing information on the harmful effects of smoking.

Decline of PGLEs of DM expresses the falling impact of DM on life expectancy. It is desirable to maintain this trend in the coming years by education of the whole society about the risks of DM, but especially by screening for this disease within the preventive physician visits. However, deaths from DM are often accompanied by cardiovascular diseases, so the improvement of life expectancy would be more significant, if the communication between these medical fields were apparent and effective. The impact on LE is the same up to the ages 50-54, what means that children and working age people could live longer than the values of life expectancy without elimination at a certain age group, in the case of total elimination of DM.

The highest increase was recognised in the PGLEs of CRD what appreciates the worsening environment, air and water pollution, solid waste, etc. It is proved that non-smokers who live together with the smokers in households suffer from respiratory allergies at least two times more than those who live with the non-smokers (3). So, not only health sector, but also environment sector should take into consideration the responsibilities for the impact of CRD on life expectancy.

A coordinated system of health cooperation between health professionals and researchers in the field of health policy, for example a system of day surgery, has lacked in Slovakia (18-21). Regular implementation of cross-sectional studies, relating to the development, impact, as well as elimination of risk factors affecting morbidity and mortality of the Slovak population, will provide a platform of the preventive and intervention strategies for non-communicable diseases (22). These programs should be launched, monitored and assessed also in the context of regional disparities in health.

\section{CONCLUSIONS}

The method of PGLEs of a certain cause of death ensure the comparability across different population, because considers age and size structure of population. Moreover, this indicator measures the competing risks of causes of death expressing the limiting value to which the lifetime could be extended. The consequences of the impacts of NCD remain serious about the quality of life and long-term high costs for treatment. Comprehensive analyses of the causes of death are a basis for creating the strategic solutions and for guiding prevention, treatment and care of the Slovak population (23-26).

\section{Acknowledgements}

This work was supported by the VEGA Project No. 1/0929/14 "Multidimensional economic and financial evaluation of the implementation process and the use of one day health care and quantification of the financial impact on the health care system in the Slovak Republic".

Our acknowledgments belong to the Ministry of Health of the Slovak Republic and the Health Policy Institute for their cooperation and support in creating new conceptions and methodologies, and for their support of our research activities.

Our thanks also goes out to the National Health Information Center (NHIC) of Slovakia for providing access to the central mortality database for the studied period as well as other studied data along with the Statistical Office of the Slovak Republic.

\section{Conflict of Interest}

None declared.

\section{REFERENCES}

1. Maresova P, Mohelska H, Kuca K. Economics aspects of ageing population. Procedia Econ Finance. 2015;23:534-8.

2. Bartak M. The management of chronic diseases in international comparison. Vnitr Lek. 2014;60(5-6):462-6. (In Czech.)

3. Asvall JE. Health21: the health for all policy framework for the WHO European Region. European Health for All series, no. 6. Copenhagen: WHO Regional Office for Europe; 1999.

4. Bleha B, Šprocha B, Vaňo B. Prognosis of population development in the Slovak Republic up to 2060. Bratislava: INFOSTAT; 2013. (In Slovak.)

5. Gavurová B, Vagašová T. The significance of amenable mortality quantification for financing the health system in Slovakia. Procedia Econ Finance. 2015;32:77-86.

6. World Health Organization. Noncommunicable diseases country profiles 2014 [Internet]. Geneva: WHO; 2014 [cited 2016 May 16]. Available from: http://www.who.int/nmh/publications/ncd-profiles-2014/en/.

7. Pol L, Thomas R. The Demography of health and healthcare. Dordrecht: Springer; 2013.

8. Eurostat database. Healthy life years and life expectancy at birth by sex [Internet]. [cited 2016 Apr 10]. Available from: http://ec.europa.eu/ eurostat/tgm/refreshTableAction.do?tab=table\&plugin=1\&pcode=tsdph 100\&language $=$ en.

9. OECD Statistics. Health status: life expectancy [Internet]. [cited 2016 Apr 10]. Available from: http://stats.oecd.org/Index. aspx?DatasetCode=HEALTH_STAT.

10. Mackenbach JP, Kunst AE, Lautenbach H, Oei YB, Bijlsma F. Gains in life expectancy after elimination of major causes of death: revised estimates taking into account the effect of competing causes. J Epidemiol Community Health. 1999;53(1):32-7.

11. Lai D, Hardy RJ. Potential gains in life expectancy or years of potential life lost: impact of competing risks of death. Int J Epidemiol. 1999;28(4):8948.

12. Liu P, Li Ch, Wang Y, Zeng W, Wang H, Wu H, et al. The impact of the major causes of death on life expectancy in China: a 60-year longitudinal study. BMC Public Health. 2014 Nov 20;14:1193. doi: 10.1186/14712458-14-1193.

13. Conti S, Farchi G, Masocco M, Toccaceli V, Vichi M. The impact of the major causes of death on life expectancy in Italy. Int J Epidemiol. 1999;28(5):905-10. 
14. Leyland AH, Dundas R, Mcloone P, Boddy FA. Cause-specific inequalities in mortality in Scotland: two decades of change. A population-based study. BMC Public Health. 2007;7:172. doi: 10.1186/1471-2458-7-172.

15. Mészáros J. Methodological guide. The calculation of life tables. The calculation of Potential Years of Life Lost. Bratislava: INFOSTAT; 2000. (In Slovak.)

16. Arias E, Heron M, Tejada-Vera B. United States life tables eliminating certain causes of death, 1999-2001. Natl Vital Stat Rep. 2013 May 31;61(9):1-128.

17. European Commission. Revision of the European Standard Population. Report of Eurostat's task force. Metodologies and working papers. Luxembourg: Publications Office of the European Union; 2013.

18. Šoltés V, Gavurová B. Analysis of selected demographic aspects of day surgery in Slovak health policy. J Appl Econ Sci. 2014;9(3):477-87.

19. Šoltés V, Gavurová B. The possibilities of day surgery system development within the health policy in Slovakia. Health Econ Rev. 2014;4:35. doi:10.1186/s13561-014-0035-1.

20. Gavurova B, Soltes M. System of day surgery in Slovakia: analysis of pediatric day surgery discrepancies in the regions and their importance in strategy of its development. E M Ekon Manag. 2016;19(1):74-92.

21. Gavurova B, Korony S. Predictive possibilities of day surgery hospitalized patients' rate in Slovakia during 2009-2013 and its health policy significance. J Appl Econ Sci. 2016;11(2):280-5
22. Gavurová B, Vagašová T. Regional differences of standardised mortality rates for ischemic heart diseases in the Slovak Republic for the period 1996-2013 in the context of income inequality. Health Econ Rev. 2016;6:21. doi:10.1186/s13561-016-0099-1.

23. Szczygiel N, Rutkowska-Podolowska M, Michalski G. Information and communication technologies in healthcare: still innovation or reality? Innovative and entrepreneurial value-creating approach in healthcare management. In: 5th Central European Conference in Regional Science (CERS): international conference proceedings; 2014 Oct 5-8; Košice, Slovak Republic [CD-ROM]. Košice: TUKE; 2014; p. 1020-9.

24. Stefko R, Gavurova B, Korony S. Efficiency measurement in healthcare work management using malmquist indices. Pol J Manag Stud. 2016;13(1)168-80.

25. Šoltés V, Gavurová B. The Functionality comparison of the health care systems by the analytical hierarchy process method. E M Ekon Manag. 2014;17(3):100-17.

26. Gavurová B, Štefko R, Bačík R. The Analysis of social services'structure in a specific region and its significance for health and social policy in Slovakia. Pol J Manag Stud. 2014;10(2):43-53.

Received October 17, 2016 Accepted in revised form December 19, 2017 